\title{
An Epistemological Theory of Argumentation for Adversarial Legal Proceedings
}

\author{
DANNY MARRERo
}

Office of the Attorney General

Department of Advanced Studies

Carrera 13 \# 73-50

Bogotá, Colombia

danny.marrero@fiscalia.gov.co

\begin{abstract}
The rhetorical view $(R)$ suggests that the goal of factual argumentation in legal proceedings is to persuade the fact-finder about the facts under litigation. However, $R$ does not capture our social expectations: we want fact-finders to know the facts justifying their decisions, and persuasion does not necessarily lead to knowledge. I want to present an epistemic theory of argumentation honoring our expectations. Under my account, factual argumentation aims to transmit knowledge to the fact-finder.
\end{abstract}

Résumé: La vue rhétorique (R) suggère que l'objectif de l'argumentation factuelle dans une procédure judiciaire est de convaincre l'enquêteur sur les faits en litige. Cependant $\mathrm{R}$ ne saisit pas nos attentes sociales: nous voulons que les enquêteurs sachent les faits qui justifient leurs décisions, et la persuasion ne conduit pas nécessairement à la connaissance. Je veux présenter une théorie épistémique de l'argumentation qui répond à nos attentes. Selon mon compte rendu, l'argumentation factuelle vise à transmettre des connaissances à l'enquêteur.

Keywords: adversarial criminal proceedings, epistemological approach to argumentation, extreme adversarialism, factual legal argumentation, knowledge attributions, rhetorical approach to argumentation, strict invariantism

\section{Introduction}

Epistemological theories of argumentation (i.e., theories using epistemological concepts and methodologies to understand problems of argumentation) have been prolific accounting for the scope of theories of argumentation, criteria for good arguments, specific argumentative forms and fallacies (Lumer 2005). I want to take this approach to another level and show that it also displays some promise of understanding factual argumentation in adversarial legal proceedings. The rhetorical view $(R)$ suggests that the goal of factual argumentation is to persuade the fact-finder about the versions of the facts under litigation. How- 
ever, $R$ does not capture our social expectations for adversarial legal systems because we want fact-finders to know the facts justifying their decisions, and persuasion does not necessarily lead to knowledge. In this paper, I want to propose the foundations of an epistemological theory of legal argumentation that would honor our social expectations.

Achieving my goal, I am going to adopt Alvin Goldman's method for evaluating inferences in the process of adjudication (2003, p. 215). Such a method has the following steps (S):

S1: Select an inference procedure as a target of analysis.

S2: Posit an aim, or set of aims, of the legal adjudication system.

S3: Determine how well the inference procedure, if used by factfinders, would promote the aim.

S4: If the inference procedure would be ineffective or deficient in promoting the aim, identify some remedies that would make the inference procedure perform better.

My inference procedure is $R$. Additionally, I submit that the aim of the legal adjudication system is to secure "substantively just treatment of individuals" (Goldman 2005, p. 164). This goal is only achieved if valid laws are correctly applied and the knowledge of the facts under litigation is achieved. Nonetheless, $R$ does not secure substantively just treatment of individuals because for $R$ the goal of legal argumentation is persuasion, and persuasion does not lead to knowledge. This is my main reason to replace $R$ in this legal context by an epistemic view. Shortly, I interpret $R$ is the result of two accounts. On one hand, it is the result of Strict Invariantism, which is the view claiming that there is one standard for knowledge attributions, and that that standard is high. Strict Invaraintism denies knowledge in legal contexts because legal inquiries do not reach the cognitive bar set for knowledge attributions. On the other hand, Extreme Adversarialism, adopting the perspective of the litigants, claims that the collection and development of evidence is meant to support the parties under litigation. If legal inquiry falls short of knowledge, and legal marshalling of evidence is partial and incomplete, then $R$ follows. Departing from $R$, I claim that if it is possible to attribute knowledge in legal contexts, and each of the participants in legal procedures has a cognitive role to play, then the goal of factual argumentation is to transmit knowledge to the fact-finder. 


\section{The rhetorical view}

As I take it, $R$ is the account holding that the goal of factual argumentation in legal proceedings is to persuade the fact-finder about the versions of the facts under litigation. Classical proponents of this principle in legal contexts are Chaim Perelman (1976), Stephen Toumin (1958) and Theodor Viehweg (1953). In this paper, I will reconstruct some of the ideas of a contemporary exponent of this approach, the American speech communication theorist Janice E. Schuetz, who has been prolific applying $R$ 's tenets to analyze famous legal cases such as Zacco and Vancetti's and O. J. Simpson's (e.g., Schuetz 1994; 2007).

To start with, she defines factual legal argumentation as "a type of reasoning [drawing] inferences from evidence in ways appropriate to legal process" (2007, p. 12). Two elements call for clarification here, the "type of reasoning" that factual legal argumentation is, and the ways in which it is "appropriate to legal process." Fleshing out the "type of reasoning" that factual legal argumentation is, I will respond to two questions: Which are the constitutive components of factual legal argumentation? And what is the inference relationship keeping these components together? Being a type of reasoning, factual legal argumentation implies "an utterance that involves a claim and support for that claim." The supported claim is related to a specific indictment, and the supporting claim, or claims, is the evidence collected in a specific case. Using Schuetz's example, “an attorney can claim that a defendant is guilty of driving while intoxicated based on blood alcohol evidence, witnesses to erratic driving, and visible manifestations of inebriated behavior, such as slurred speech and inability to walk a straight line" (2007, p. 12).

Identifying the inferential link keeping the indictment and the evidence together, Schuetz claims that factual argumentation is a type of informal reasoning different from deduction and induction. Nevertheless, she does not make any reference to a defeasible reasoning, as some theories of legal argumentation do (...). Instead, she claims that the components of legal argumentation are linked together in a coherent narrative. To clarify, factual legal argumentation is a type of reasoning seeking "to persuade without using explicit logical forms such as syllogisms" (p. 12). Therefore, indictment and evidence are not linked together by a deductive inference. Factual legal argumentation is not inductive either. Schuetz justifies this point borrowing Perelman's distinction between practical and theoretical reasoning. While the former "involves value judgements about the quality of both acts and persons, [the latter] concentrates on attempts to 
establish a probable truth" (Schuetz 2007, p. 16). Factual reasoning is not a type of theoretical reasoning because it has "the goal of persuading judges and/or jurors" (p. 13), and it does not "[attempt] to establish a probable truth," as it should be done by inductive reasoning. In Schuetz' words,

In theory, the goal of legal argumentation is to discover the probable truth of an action. Perelman's work emphasized how practical and theoretical reasoning converge in legal practice. The subsequent case studies emphasize the practical over the theoretical and identify how attorneys and judges transform theoretical argumentation into practical reasoning using narratives, dramas and games. (Schuetz 2007, p. 16)

Unfolding this paragraph, I interpret that Schuetz identifies the received view with the tenet that "the goal of legal argumentation is to discover the probable truth of an action." But she disagrees with this principle. This is indicated by the expression "In theory" at the beginning of the quote, and by her notion of attorneys' and judges' argumentative practices. For her, "attorneys and judges transform theoretical argumentation into practical reasoning." Recalling her definitions of these types of reasoning, attorneys and judges do not "[concentrate] on attempts to establish a probable truth," but on "value judgements about the quality of both acts and persons."

The means to transform theoretical into practical reasoning is through "narratives, dramas and games". Therefore, stories told in criminal trials connect the indictment and the evidence through a story theme in a consistent and complete way. In Schuetz' words, 'attorneys construct their stories from the narrative fragments provided by the witnesses and emphasize the segments of the testimony their case theory and story theme" ( $\mathrm{p}$. 20). The goal of this stories is to persuade the trier of facts: "[a]ttorneys and witnesses use narratives to convince jurors and/or judges of the probability and fidelity of their stories in relation to the disputed civil and criminal trials" (p. 18). Notice that the expression, "probable," in this fragment, does not refer to objective probability, but to subjective probability. This is confirmed by the fact that, for Schuetz, factual narratives in legal contexts do not have to be true, but they should be persuasive. "Stories presented by one of the sides of the case may be untrue, but they persuade jurors and judges because they seem more probable and resonate with juror's experiences more than stories presented by the other side of a case" (p. 18). This differentiates her account from narrative-based theories of legal argumentation demanding the stories to be anchored in the legal

(C) Danny Marrero. Informal Logic, Vol. 36, No. 3 (2016), pp. 288-308. 
evidence (e.g., Wagenaar, van Koppen, and Crombag 1993), that is, to be true.

Moving on to the ways in which factual argumentation is "appropriate to legal process," it is important to point out that Schuetz endorses a theory of the law as a means of conflict resolution: "the law exists to solve human problems and to regulate human conduct" (p. 3). Such a resolution is achieved through a verdict (p. 22). To be sure, in modern systems of adjudication, the triers of facts "are expected to review the facts and discern the guilt or innocence of the defendant based on the criminal charges" (p. 40). The condition for adjudication is the presentation of the evidence constituting the facts under litigation. Temporarily speaking, firstly, "criminal trials hear and see evidence to establish case facts, and judge and/or jurors then decide whether or not those facts support the charges or complaints" ( $p$. 36). How does factual legal argumentation promote conflict resolution through verdicts? On one hand, narratives provide the background information to understand the conflict under account. In this sense, Schuetz states, "the legal issues embedded in the attorney's narratives create cognitive frameworks for jurors to use to interpret the law and decide facts according to their coherence, probability, and believability" (p. 45). On the other hand, factual legal argumentation allows for a better understanding of the parties' allegations because "stories enable juries to connect the information to a story theme, make inferences that fit the various parts of the story with a theme, and decipher whether the story is consistent and complete" (p. 19).

\section{A problem for $R$ : The cognitive aspirations of legal proceedings}

My departure from $R$ starts with my interpretation of $S 2$. To recall, this is Goldman's methodological step demanding to "Posit an aim, or set of aims, of the legal adjudication system". Some clarifications are required. According to Goldman, theories of legal proceedings fall into two categories: either they are pluralistic or unified (2005, pp. 163-164). Pluralistic accounts hold that legal procedures have different aims, no one of which is prior to the other (e.g., fairness, justice, impartiality, allowing pacific coexistence, seeking the truth, protection of civil rights, etc.). Unified theories, in contrast, explain procedures with reference to one main end. They do not hold that legal procedures actually achieve the selected goal; better yet, they use it as an explanatory resource to clarify the main activities performed in legal procedures. Within this second alternative, one can find 
pure unified theories and impure unified theories. Pure accounts state that the legal practices taken into account are subsumable in one exclusive desideratum. Impure unified alternatives defend that although the aim of legal procedures is such an exclusive aim, it is possible to recognize alternative goals coexisting with the dominant rationale.

Schuetz's account is a unified pure theory, for it suggests that legal proceedings aim to resolve disputes, or differences of opinion, and she does not prevent alternative goals to be achieved by legal proceedings. From my perspective, the problem for unified pure theories is that they are too vulnerable to counterexamples showing that the legal system is expected to achieve goals that are not included in the exclusive end. For instance, a theory that claims that the exclusive end of a system of adjudication is to resolve disputes would be compatible with the method of adjudication solving disputes through flipping a coin, and a rule saying that whoever picked heads wins. Yet this does not seem right because the law not only wants to solve disputes, but to achieve justice, which is another possible desideratum for legal systems. I believe that the problem for pluralistic accounts is that they cannot account for the conflicts that could arise between the multiplicity of ends they propose because all of them have the same importance. With this in mind, I propose an impure unified theory. With Goldman (2005), I believe that the aim of legal procedures is to secure "substantively just treatment of individuals." This goal is only achieved if valid laws are correctly applied and the knowledge of the facts under litigation is achieved (p. 164).

Continuing with $S 3$, I submit that factual legal argumentation cooperates with the subordinate goal of achieving knowledge of the facts under litigation. $R$ is the view holding that the goal of factual argumentation in legal proceedings is to persuade the fact-finder about the versions of the facts under litigation. But, the belief the fact-finder is supposed to be persuaded of is not qualified; that is, it is not subject to further conditions (Lumer, 2010, pp. 45-46). As a consequence, a factfinder could be persuaded of something that is true by chance or of something that is not true; in one case or the other, the factfinder does not know what we are expecting him/her to know. In Schuetz's account (2007), this lack of qualification becomes explicit when she recognizes that,

"[s]ome of the stories attorneys tell are factual, and others are fictional. Stories presented by one side of the case may be untrue, but they persuade jurors and judges because they seem more probable and resonate with jurors' experiences more that the other side of a case" (p. 19)

(C) Danny Marrero. Informal Logic, Vol. 36, No. 3 (2016), pp. 288-308. 
Even worse, she paraphrases Walter R. Fisher to highlight that "some clever and unethical narratives may seduce audiences into believing false information" (as cited in Schuetz 2007, p. 19). This is not to say that Schultz promotes unethical or false argumentation in legal proceedings. In fact, she thinks that legal principles shape legal narratives with "ideals such as respectful relationships, truthful messages, and fair use of strategies and tactics" (p. 51). My point is that even with all these ideals, $R$ does not satisfy our cognitive expectations for legal proceedings.

First, under $R$, triers of facts do not know, even if they justifiably and truly believe. Given that the belief the fact-finder is supposed to be persuaded of is not qualified, he/she could be persuaded of something that is true by chance, as in the following case.

Two officers plant cocaine in an automobile, and they then give unrebutted testimony at the driver's trial that they found the cocaine after a consensual search of the car. The driver, concerned about his prior record coming out on cross-examination, does not testify and offers no real defense. The fact-finder convicts the driver after finding the officers credible. Now, unbeknownst to everyone except the defendant, he really did have cocaine in the car that never was discovered. (Pardo 2005, p. 322)

As any other Gettier-type case, Pardo's case shows that the factfinder does not know that the defendant had cocaine. However, the fact-finder's belief that the defendant had cocaine is true, and the fact-finder is justified in believing that it is true, provided the two officer's "unrebutted" testimony. In other words, this case shows that the fact-finder did not know that the defendant had cocaine; this finding was true, but just as mere coincidence. According to Pardo, in modern legal proceedings, fact-finders are expected to sentence based on the knowledge of the facts under litigation and not on coincidentally true findings.

Second, under $R$, triers of facts do not know because they do not justifiably believe. This is confirmed by an argument from cognitive sciences. Empirical studies have shown that prosecutors and criminal investigators who are held accountable of their success in persuading are more prone to minimize, or ignore, evidence inconsistent with their hypothesis than the ones held accountable by a different criteria (e.g., using the right procedure for decision making or achieving the best outcome) or no criteria at all (O'Brian 2009). If prosecutors and criminal investigators are prone to minimize, or ignore, evidence inconsistent with their hypothesis, then prosecutors and criminal investiga- 
tors are not justified in believing that the defendant is guilty. In adversarial criminal proceedings, fact-finders are expected to render a verdict based upon the information and arguments that prosecutors and criminal investigators present before them at trial. If prosecutors and criminal investigators are not justified in believing that the defendant is guilty, fact-finders will not be necessarily justified in believing that the defendant is guilty. Therefore, falling short of our social expectations, under $R$, factfinders do not know the facts that justify their verdicts.

\section{Strict invariantism and extreme adversarialism}

Moving to $S 4$, my contention is that $R$ does not take into account the cognitive aspirations of legal proceedings because it is the consequence of two accounts: strict invariantism and extreme adversarialism. Strict invariantism is the view that the standard of knowledge is one, and that it is high. For instance, some strict invariantists claim that the standard of knowledge is scientific knowledge. If a putative knower does not satisfy the standards of scientific knowledge, then he/she does not know. Extreme adversarialism is the view claiming that the nature of legal proceedings is adversarial, and therefore, the factual reconstructions in legal proceedings are biased and incomplete. If legal agents cannot meet the standards of scientific knowledge, and their factual reconstructions are biased and incomplete, then the most they can do is to try to persuade the fact-finder of their versions of the facts under litigation.

Let me illustrate these ideas with Susan Haack's legal epistemology. To begin with, let's unpack her concept of inquiry. Broadly speaking, "inquiry is an attempt to discover the truth of some question or questions" (Haack, 2004, p. 45). The starting point of inquiry is a question, which perturbs a cognitive agent. In solving this issue, he/she formulates one hypothesis and starts looking for evidence, which confirms it. Not having confirmation, the agent either modifies or abandons his/her initial conjecture. When the evidence leads to the true answer under consideration, the inquirer's aim is achieved. It is commonly accepted that inquiry is a constitutive part of legal systems because the justice that they want to achieve depends on two sides of the same coin. On one side, justice is conditioned by the application and administration of just laws. On the other side, it is a consequence of the truth determination of legally relevant facts. The latter shows that the law is also one activity whose core is inquiry. Haack counter-argues this position juxtaposing science and law. Since the core of science is inquiry, it provides 
an archetype which law would fulfill if its core were inquiry as well. Yet, the law does not conform to science. In Haack's words,

If the legal system were in the same business as history, geography, or as physics and the other sciences, its way of conducting that business would be peculiar, and inefficient, to say the least. But the law is really not in exactly the same business (2009, p. 13).

For Haack, the main differences between science and law are the following (see Table 1 below). Firstly, the equation of the three main elements of the concept of inquiry (i.e., question, evidence and answer) is different in science and law. A scientific method starts with a question, which encourages the search for evidence that could provide an answer for the original issue. Although legal proceedings also start with a question, unlike science, legal agents first provide answers to their initial questions and then look for the evidence, which supports their position. Secondly, the aim of science is to formulate, examine and answer questions, which explain how the world works. Alternatively, a legal procedure is a non-violent social means of conflict resolution. To be sure, the legal procedure is aimed to produce a verdict of either guilt or liability, or non-guilt or non-liability according to a body of evidence. This decision ends a dispute between two adversarial parts (e.g., prosecutors vs. attorneys, or petitioners vs. respondents). Third, the interest of science is not only to solve a question, but also to provide explanations for phenomena. Hence, the object of science is general law, which explain particular cases. Legal proceedings, instead, attain their goals through particular cases. Fourth, when scientific results seem to be unsatisfactory under new evidence, scientists wonder about the problems of their partial results and, if necessary, those are modified. In this sense, science is fallible. In contrast, the satisfaction of legal resolutions implies both prompt and definite verdicts. For one thing, extremely slow justice is not justice; for another, constantly modified verdicts conduct legal insecurity. Fifth, science is progressive, whereas law is conservative. To clarify, scientific problem-solving dynamics are reiterative because once a scientific question is solved, a new issue is posited. This leads to progressivism because, normally, the new questions are analyzed and answered using previous results. This contrasts to the importance of precedent in legal decisionmaking. Tackling the atomism of their case-based orientation, legal systems unify verdicts using previous judicial decisions as patterns for future decisions. Next, whereas science generally 
has unlimited time in order to solve a problem, legal problem solving generally has much more rigid time constraints. Finally, scientific investigation is free from formalities, while law establishes rituals for the resolution of social conflicts. In other words, in their investigations, scientists do not use standardized protocols. What is important is the explanatory power of their theories, not the way through which they construct them. Legal resolution of conflicts, on the contrary, homogenizes legal behavior through legal procedures. If legal agents do not follow the procedural itinerary, they cannot achieve their objectives (Haack, 2009, pp. 7-15; 2004, pp. 45-50; 2003, pp. 205-208).

Table 1: Juxtaposition Between Law and Science

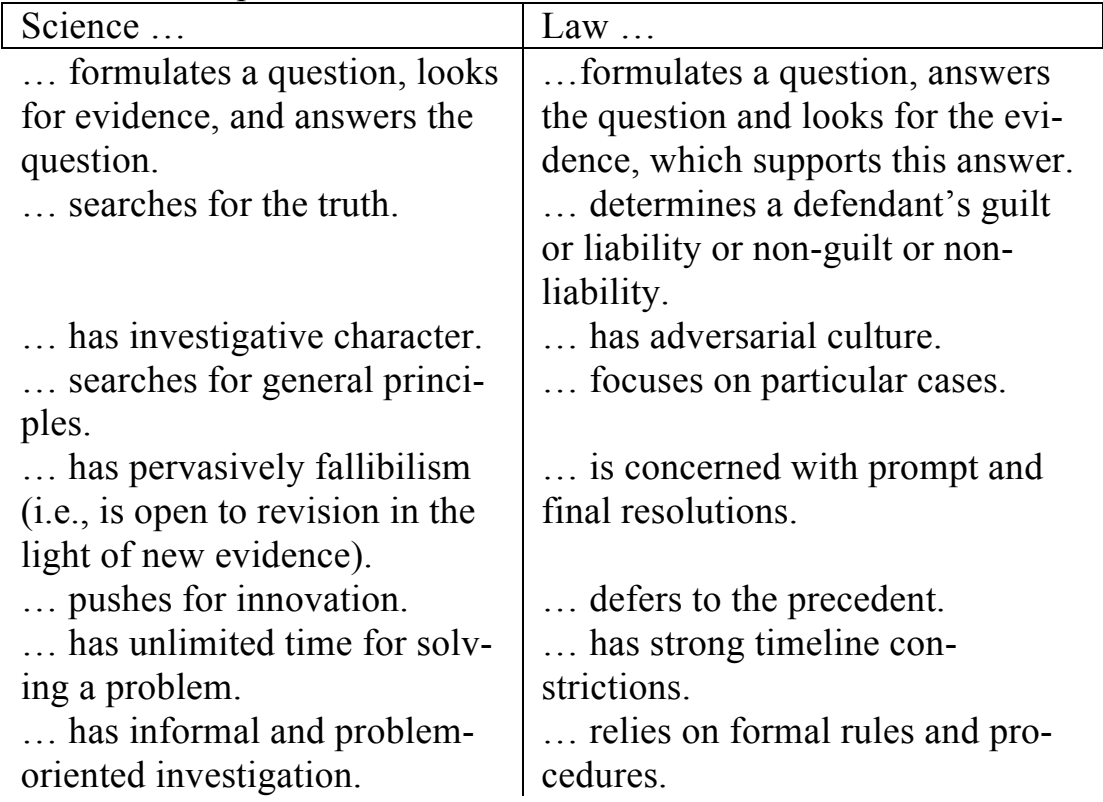

To sum up, Haack's strict invariantism fixes the standards for knowledge with the concept of scientific inquiry. If a putative knower does not satisfy the standards of scientific inquiry, then he/she does not know. Even though Schuetz does not fix explicit high and invariable standards for knowledge that legal systems of inquiry should achieve, she, interpreting Stephen Toulmin, differentiates the standards required for science from the standards required for legal systems.

The work of Stephen Toulmin $(1960,2001)$ explained how fields or jurisdictions of arguments have different goals, rules and standards of evidence. The strength or weakness of the argument depends on how it meets the general standards of the field. Legal argumentation is a 
specific field with its own peculiar standards and rules. The reasoning in the legal field is subject to standards that are different from reasoning in science and religion. (Schuetz 2007, 16)

This strategy allows her to state that factual legal argumentation does not need to be factive, but persuasive.

To continue, Haack's extreme adversarilism comes from a wrong generalization. She assumes the advocate's perspective and defines all law from this angle:

The advocacy that is at the core of the adversarial process is a very different matter from inquiry $[. .$.$] the obligation$ of an attorney, qua advocate, is to make the best possible case for his client's side of the dispute-including playing up the evidence that favors his case, and explaining inconvenient evidence away if he can't get it excluded. (2009, p. 13)

But, why should we privilege advocacy and not fact-finding which is the obligation of the triers of facts, investigators and detectives? Haack could replay it in this way, "This is not to deny that inquiry plays a role in the legal process [...], but it is to deny that inquiry is quite as central to the law as it is to science" (2009, pp. 12-13). However, if someone asks for a positive account for the role of inquiry in legal procedure, one more time, she does not provide a positive response. Schuetz is an extreme adversarialist, for she understands legal proceedings exclusively from the perspective of litigants. In her words,

Legal proceedings are contests that feature adversaries with competing goals. These contests begin with an analysis of the evidence and arguments of a case. The attorneys act as game players; they adopt strategies and tactics that navigate the rules and try to outwit each other in their effort to win a verdict (2007, p. 24).

\section{An epistemological theory of argumentation for adversarial legal proceedings}

If my intuitions are right, a theory of argumentation taking into account the cognitive aspirations of legal proceedings should be able to provide a theory of knowledge attributions for legal contexts and a theory of cognitive division of work for legal proceedings. The reason for this is that if it is correct to attribute knowledge to legal agents, and the parties are part of a cognitive system where each of them has a role to play in the achievement

(C) Danny Marrero. Informal Logic, Vol. 36, No. 3 (2016), pp. 288-308. 
of legal knowledge, then the role of legal argumentation is to transmit knowledge.

\subsection{Knowledge attributions in legal contexts}

Let me start with a theory of knowledge attributions for legal contexts. As I take it, there is a knowledge attribution when an agent, the attributor, asserts that another agent, the putative knower, knows that $p$. By the same token, there is a knowledge denial when the attributor asserts that the putative knower does not know that $p$. The problem of knowledge attributions is, then, whether the attributor correctly asserts that the putative knower knows (or does not know) that $p$. Knowledge attributions and denials differ from other knowledge relations such as having or lacking knowledge, getting or not getting knowledge, detecting or not detecting knowledge, and so on. For this paper, it is important to differentiate the problem of knowledge attribution from the problem of knowledge possession, which is whether an agent knows that $p$. While the latter is a first-order knowledge relation, the former is a second-order (or meta-) knowledge relation. That is, the object of a knowledge attribution is a knowledge possession. In one sentence, the problem of knowledge attribution is not whether a putative knower knows that $p$, but under which conditions it is correct to assert that a putative knower knows that $p$.

My working hypothesis is that a knowledge attributor correctly asserts that a putative knower knows that $p$ when the putative knower properly closes or advances his/her cognitive agenda. The conceptual background of my account comes from the notions of agent and agenda. Shortly, an agent is an entity doing something. Agendas are the objectives agents are disposed to achieve (Gabbay and Woods, 2003, pp. 183-185; 195-219). In this sense, "[a]n agenda is something like a network of tasks or programmes to be discharged" (Gabbay and Woods, 2003, p. 182). Agendas and sub-agendas have conditions of closure determining both the actions an agent is expected to perform in order to achieve his/her objective, and the time range in which he/she should do it. An agenda in course is properly closed when agents deploy their resources in such a way that its conditions of closure are obtained, but agendas are not closed simpliciter. Instead, the agent's matching of the conditions of resolution comes in degrees. An agenda in course is properly advanced when some of its closure conditions have been obtained, but not all of them yet (Gabbay and Woods, 2003, p. 215).

(C) Danny Marrero. Informal Logic, Vol. 36, No. 3 (2016), pp. 288-308. 
"An agenda may involve things an agent desires to know, or would find it useful to know for the transaction of certain tasks, or the making of certain decisions in some contextually circumscribed circumstances or states of affairs he is disposed to realize" (Gabbay and Woods, 2003, p. 183). I refer to this as cognitive agendas. A cognitive agenda is, then, a set of questions that a cognitive agent wants, or needs, to answer for the achievement of his/her objectives. Agents pursue cognitive agendas for the sake of knowledge or they are sub-agendas, which enable them to achieve other purposes. Theories of epistemic risk claim that it is possible to differentiate between two types of cognitive agents in accordance with their attitude toward epistemic risk taking (Fallis, 2007; Levi, 1962; Mathiesen, 2011; Riggs, 2008). Whereas some agents withhold the acceptance of a proposition until all the information has been obtained, other agents act with less caution and accept propositions with incomplete information. Theories of epistemic risk claim that agents accept propositions with incomplete information because of practical reasons. Think of a resident medical officer dealing with clinical emergencies on behalf of admitting consultants in juxtaposition with a professor of biochemistry studying the chemical composition of bacteria resistant to penicillin. Although both, the resident medical officer and the biochemistry researcher, want a true answer for their inquires, the latter, but not the former, can withhold it until all the information has been collected. Cognitive agents adopting cognitive agendas for the sake of the achievement of a practical goal are practical doxastic agents. Theoretical agents, differently, pursue cognitive agendas when it leads to "the truth and nothing but the truth."

According to Gabbay and Woods, there are two factors that determine the different types of cognitive agents (2005, p. 11). Firstly, there is the degree of command of resources (time, information and computational capability) an agent needs to advance or close his/her agendas. Secondly is the height of the cognitive bar that the agent has set for him/herself. With this in mind, Gabbay and Woods incorporate a hierarchical approach to agency. It postulates a hierarchy in which agents are placed in light of their interests and their capacities. In this model, practical doxastic agents would be placed towards the bottom of the hierarchy and theoretical agents would be higher up (see Table 2 ). While practical doxastic agents "perform their cognitive tasks on the basis of less information and less time than they might otherwise like to have", theoretical agents "can wait long enough to make a try for total information, and they can run the calculations that close their agendas both powerfully and precisely" (pp. 11-12).

(C) Danny Marrero. Informal Logic, Vol. 36, No. 3 (2016), pp. 288-308. 


\section{HIGHER LEVEL}

Theoretical agents

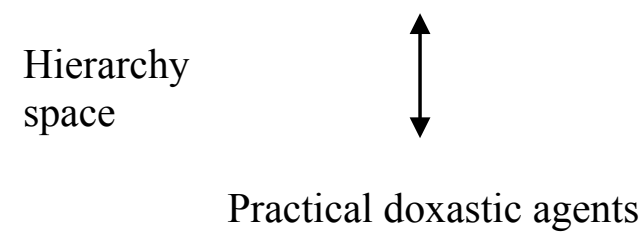

\section{LOW LEVEL}

Table 2. Hierarchy of Cognitive Agents

My view is that, in terms of the hierarchy, legal agents are practical doxastic agents ranked higher than individuals solving dayby-day-practical problems such as crossing a street, looking for an address or cooking a meal; yet, legal agents are placed at a lower level than are pure theoretical agents such as the researchers of the National Aeronautics and Space Administration (NASA). To be sure, a legal agent commands more cognitive resources than an individual solving day-by-day-practical problems. What is expected in the adversarial system of adjudication is that the litigants, with the incentive of winning the case, look for all the relevant information for the legal inquiry. Additionally, they work in teams of inquirers, witnesses, and experts who seek to make their versions of the case stronger. The idea is that these parallel inquiries exhaust all the relevant information to be known. Another important difference between an individual solving day-by-day practical problems and a legal agent is the cognitive aim they are disposed to achieve. Legal procedures have a high cognitive aim, namely, to determine the truth of the events under litigation. Legal agents serve this goal in different ways. This is true even for litigants who apparently only serve their respective side's interests. When they take part in a legal inquiry, their vantage point clarifies aspects of the events that are inaccessible by the officials. Individuals, on the contrary, are not always interested in the truth. This explains why individuals are naturally hasty generalizers, or why they do not always use truth-preserving strategies of reasoning (Gabbay and Woods, 2005, pp. 23-25; Woods, 2013, p. 212).

Even though legal agents are ranked higher than individuals, they do not have the resources that inquirers such as NASA's scientific groups have. Since legal inquiries have strong timeline constrictions, they make decisions with incomplete and partial information. Furthermore, in dealing with facts, 
legal systems expect legal agents to reason as individuals and not as experts. Experts take part in legal discussions as qualified witnesses, but they are not able to make the ultimate decision. The institution of the jury in adversarial systems illustrates this point. Prima facie, any citizen can be part of the jury, unless he/she has expert knowledge about the actual issues under consideration. Given this case, the jury is excluded. Alternatively, in legal systems in which the fact-finder should be an educated citizen, what is expected is that such a qualified citizen be educated in the law, but not in factual matters such as forensic science. To sum up, legal agents have the computational capacity of an average person, or a reasonable person (Woods 2011, p. $226 ; 2015$, p. 225). Therefore, they are ranked lower than theoretical agents, but higher than individuals.

To recall, from my perspective, knowledge attributions have the purpose of stating that a cognitive agenda has been properly closed. Given that the object of knowledge attributions is cognitive agendas, the conditions under which knowledge is properly attributed depends on the nature of the cognitive agenda claimed to have been properly closed or advanced. If my ideas are right, knowledge attributions in legal contexts depend on the nature of the cognitive agenda under account and not on standards belonging to foreign agendas such as the scientific ones. To be sure, legal proceedings impose cognitive agendas on its participants depending upon the activities they have to perform in each procedural stage. These agendas include closure conditions for the required actions. When such standards are not met, knowledge attributions are not justified. For instance, criminal investigations are one of the sub-agendas of the prosecution in criminal cases. The ultimate agenda of a prosecution is to show, beyond a reasonable doubt, that a defendant committed a crime. When the prosecution does not satisfy this burden, the innocence of the defendant is assumed. The goal of criminal investigations is to present a case to the prosecutor. This includes a cognitive agenda of determining whether a crime has been committed, and who did it. Such cognitive agenda is closed or advanced in two ways: either determining that there is good evidence that there was an occurrence of a crime, or determining that there is not good evidence for the occurrence of a crime. Imagine a criminal investigator wondering whether there is good evidence for the occurrence of a crime. Only relevant information that is processed in the right way allows the criminal investigator to come to know if there is good evidence that the crime occurred. There are two main sources of information in criminal investigations: state of affairs, or physical evidence, such as fingerprints, sound recordings, photographs, and so on, 
plus the testimony of eyewitnesses and other collaborators. Let me focus on testimonial evidence. Testimonies are relevant when they provide information useful to advance the agenda of the criminal investigation. That is, they provide information useful to determine that either there is good evidence for the hypothesis that a crime occurred, or there is not good evidence for such hypothesis. When this is the case, criminal investigators attribute knowledge to the eyewitness, victims and other collaborators.

\subsection{The cognitive division of work for legal proceedings}

The cognitive division of work in legal contexts becomes clear if we understand epistemic justification in legal contexts as a type of belief-dependent cognitive process. This understanding calls for some terminology from Alvin Goldman's theory of epistemic justification. To clarify, theories of justification are accounts specifying the conditions under which a person is justified in believing (Goldman, 1979, p. 3). Consequently, a theory of justification adopts the next structure:

$S$ is justified in believing that $p$ if and only if:

$$
\begin{gathered}
C_{1} \\
C_{2} \\
\ldots \\
C_{\mathrm{n}}
\end{gathered}
$$

In this structure, $S$ stands for a cognitive agent, $p$ for a fact or proposition, and $C_{1} \ldots C_{\mathrm{n}}$ are the conditions for justificatory status.

As a first approximation, Goldman suggests that:

$S$ is justified in believing that $p$ if and only if:

$C: p$ results from a reliable cognitive process.

In this account, cognitive process is defined as a function with inputs that have beliefs as outputs (p. 11). Two types of processes are important here. Firstly, the belief-dependent processes have other beliefs as inputs. Secondly, the belief-independent processes do not have other beliefs as inputs (p. 13). Perception is an example of a belief-independent process. Reasoning, which includes antecedent beliefs within their premises, is an instance of a belief-dependent process. Following this terminology, there are two kinds of beliefs. A belief-independent belief is the output of a belief-independent process, and a belief-dependent belief is the result of a belief-dependent process. Finally, reliability

(C) Danny Marrero. Informal Logic, Vol. 36, No. 3 (2016), pp. 288-308. 
"consists of the tendency of a process to produce beliefs that are true rather than false" (p. 10). While in belief-dependent processes reliability depends on the truth of the inputs (i.e., it is conditional), in belief-independent processes, reliability is categorical. From these distinctions, Goldman suggests two forms for evaluating justificatory status.

The first form is for the belief-independent processes:

$S$ is justified in believing that $p$ if and only if:

$C_{1}: p$ is a belief-independent belief, and

$C_{2}: p$ is the result of a categorically reliable process.

The second form is for the belief-dependent processes:

$S$ is justified in believing that $p$ if and only if:

$C_{1}: p$ is a belief-dependent belief, and

$C_{2}: p$ is the result of a conditional reliable process.

If my interpretation of Goldman's ideas is not wrong, legal knowledge is a type of belief-dependent process. This formula captures the core of my interpretation:

A legal agent is justified in holding an epistemic judgment $(j)$, in a legal procedure, if and only if:

$C_{1}: j$ depends on the procedural interventions of other participants in the legal procedure, and

$C_{2}: j$ is the result of the truth-conduciveness of the legal procedure.

I will explain these two conditions for legal knowledge below, but a previous distinction is required. Goldman, in Knowledge in a Social World, states: "[n]otice that I am speaking of judgments rather than beliefs. The reason for this deviation is that the palpable outputs of legal deliberations are not private beliefs but public judgments of guilt and innocence, liability or non liability" (1999, p. 272). This is an important distinction between general epistemology and legal epistemology. While the former studies epistemic justification independently of actual argumentation, the latter is concerned with epistemic justifications publicly justified in legal contexts.

To continue, legal agents do not perceive the facts under litigation directly; rather, they form their judgments from different sources of legal knowledge. To mention the most common examples, the presumed fact that " $Y$ was murdered by $X$ " is not perceived by the detective who looks for relevant evidence that establishes whether $X$ murdered $Y$. Neither the prosecutor who 
publically accuses $X$ of murder, nor $X$ 's attorney perceived the fact under litigation. Instead, they build their respective versions of the case with information provided by their side's detectives, witnesses, material evidence, etc. Finally, the trier of factsjudge or jury - does not perceive the alleged facts. On the contrary, he/she receives the information from the witnesses who are examined and cross-examined at trial. As a consequence, $j$ depends on the procedural interventions of other participants in legal proceedings.

If $j$ depends on the procedural interventions of other participants in legal proceedings, then $j$ is not required to be categorically reliable, but conditionally reliable. In other words, the truth of $j$ depends on the truth of its inputs. Three examples proposed by Goldman illustrate types of cues that juries find very probative (2003, p. 221). First off, imagine a witness identification testimony where the witness points his/ her finger at the defendant and states, "This is the one." With this information, the trier of facts would probably decide that $X$ murdered $Y$ if the witness pointed at $X$. However, identifications are not $100 \%$ accurate. Witnesses also make mistakes, and this failure is transferred to the fact-finders' decision. The second example is when a person confesses that he/she did the crime under inquiry, a judge (or a jury) tends to believe that the person who confessed actually did the crime. But, some confessions are produced by police intimidation or by the possibility of a plea bargain that ends in a negotiation with less serious crime charges for the offender. If $X$ confesses that he murdered $Y$ when he did not do it, all legal judgments drawn from $X$ 's confession will not be true. Finally, when a technical clarification is needed to understand the alleged facts, the trier of facts will rely on expert testimonies. Since one of the most important criteria for accepting an expert assertion is the credibility that the expert witness has, some inaccurate expert testimonies are incorporated into legal judgments. Ultimately, the credibility an expert has is not an epistemic criterion (i.e., it is not related to seeking the truth). To conclude, "we cannot expect any [inferential process in the field of law] to make correct (truthful) inferences if its inputs or premises are substantially inaccurate. 'Garbage in, garbage out', as the saying goes" (Goldman, 1999, p. 219).

Under this account, the partisan argumentation might honor the cognitive aspirations of legal proceedings. On one hand, it is correct to attribute knowledge to the parties if they properly close their cognitive agendas. On the other hand, the parties' one-sided argumentation has a specific role to play in legal cognitive systems. 


\section{Conclusion}

To briefly conclude, let's look at how the epistemic theory of legal argumentation in legal contexts would respond to the main arguments against $R$. To recall, there is a cognitive aspiration in legal proceedings that theories of legal argumentation should take into account. In other words, theories of legal argumentation are supposed to show how legal argumentation leads to knowledge. However, $R$ does not respond to our social expectations. On one hand, given that under $R$, the belief a fact-finder is supposed to be persuaded of is not qualified, the trier of facts could be persuaded of something that is true by chance. Consequently, the fact-finder does not know, even if he/she justifiably and truly believes. On the other hand, since under $R$ the beliefs trier of facts are supposed to be persuaded of do not have to be true or accurate, then $R$ makes legal agents prone to cognitive bias. As a consequence, they do not know because they do not justifiably believe.

The epistemic view of argumentation holds that "the standard output of argumentation is knowledge or justified belief in the epistemological sense" (Lumer 2005, p. 190). Being precise, an epistemological theory of legal argumentation would defend that the standard output of legal argumentation is "justified judgment" and not mere "justified belief." "The reason for this deviation is that the palpable outputs of legal deliberations are not private beliefs but public judgments of guilt and innocence, liability or non liability". This theory would serve better the end of securing a substantively just treatment of individuals because, from this perspective, arguments should be constituted by true propositions. Consequently, an epistemic theory of legal factual argumentation would orient the fact-finder better about the facts under litigation.

Loosely speaking, an epistemic theory of argumentation rules out epistemic luck because knowledge depends upon the closing of cognitive agendas whose closure conditions demand specific cognitive actions. In addition, an epistemic theory of factual argumentation would not allow for cognitive bias because, in general terms, an agent is justified in believing something if there are not defeaters for that belief. The problem with cognitive bias is that although cognitive agents have defeaters for their beliefs, they ignore them, minimize them or think they are unreliable. An epistemological theory of actual argumentation in legal contexts takes defeaters into account, and might be useful reducing cognitive bias because it makes arguers accountable of the evidence contrary to their positions. 


\section{References}

Fallis, Don. 2007. Attitudes towards epistemic risk and the value of experiments. Studia logica 86(2): 215-246.

Gabbay, Dov and John Woods. 2003. Agenda relevance. Amsterdam: Elsevier.

Gabbay, Dov and John Woods. 2005. The reach of abduction. Insight and trial. Amsterdam: Elsevier.

Goldman, Alvin. 2005. Legal evidence. In The Blackwell guide to the philosophy of law and legal theory, eds. Martin Golding and William Edmunson, 163-175. Maden: Blackwell Publishing.

Goldman, Alvin. 2003. Simple heuristics and legal evidence. Law, probability and risk 2(3): 215-226.

Goldman, Alvin. 1999. Knowledge in a social world. Oxford: Clarendon Press.

Goldman, Alvin. 1979. What Is Justified Belief? In Justification and knowledge, ed. George Pappas, 1-25. Dordrecht: Reidel.

Haack, Susan. 2009. Irreconcilable differences? The uneasy marriage of science and law. Law and contemporary problems 72(1): 1-23.

Haack, Susan. 2004. Epistemology legalized: Or, truth, justice, and the American way. The American journal of jurisprudence 49(1): 43-61.

Haack, Susan. 2003. Inquiry and advocacy, fallibilism and finality: Culture and inference in the science and in the law. Law probability and risk 2(3): 205-214.

Levi, Isaac. 1977. Epistemic utility and the evaluation of experiments. Philosophy of science 44(3): 368-86.

Lumer, Christoph. 2005. The Epistemological Theory of Argument-How and Why? Informal logic 25(3): pp. 213-243.

Lumer, Chistoph. 2010. Pragma-Dialectics and the Function of Argumentation. Argumentation 24(1): 41-69.

Mathiesen, Kay. (2011). Can groups be epistemic agents? In Collective epistemology, eds. Hans Schmid, Daniel Sirtes and Marcel Weber, 23-44). Frankfurt: Ontos Verlag.

O'Brien, Barbara. 2009. Prime suspect: An examination of factors that aggravate and counteract confirmation bias in criminal investigations. Psychology, policy and law 15(4): 315334.

Pardo, Michael. 2005. The field of evidence and the field of knowledge. Law and philosophy 24(4): 321-392

Perelman, Chaim. 1976. Logique juridique. Nouvelle rhétorique. Paris: Dalloz.

Riggs, Wayne. 2008. Epistemic risk and relativism. Acta analytica 23(1): 1-8.

(C) Danny Marrero. Informal Logic, Vol. 36, No. 3 (2016), pp. 288-308. 
Schuetz, Janice. 1994. The logic of women on trial. Case studies of popular American trials. Carbondale: Southern Illinois Evicersity Press.

Schuetz, Janice. 2007. Communicating the law. Lessons from landmark cases. Long Grove: Waveland Press.

Toumin, Stephen. 1958. The uses of argument. Cambridge: Cambridge University Press.

Viehweg, Theodor. 1953. Topik und jurisprudenz: Ein Beitrag zur rechtswissenschaftlichen. Grundlagenforschung. Munik: H. C. Beck.

Wagenaar, Willem; van Koppen, Peter and Crombag, Hans. (1993). Anchored Narratives: The Psychology of Criminal Evidence. New York: St Martin's Press and Hertfordshire.

Woods, John. 2013. Errors of reasoning: Naturalizing the logic inference. Milton Keynes: College Publications.

Woods, John. (2011). Abduction and Proof: A Criminal Paradox. In Approaches to legal rationality, eds. Dov Gabbay, Patrice Canivez, Shahid Rahman and Alexandre Thiercelin, 217-238. Dordrecht: Springer.

Woods, John. (2015). Is legal reasoning irrational? An introduction to the epistemology of law. London: College Publications. 